\title{
Resíduos sólidos na construção civil: analise da gestão frente aos impactos causados
} ao meio ambiente

\author{
Solid waste in construction: management analysis of impacts impacted on the environment
}

Residuos sólidos en la construcción: análisis de gestión de impactos impactados en el medio ambiente

Beatriz Queiroga Camilo

ORCID: https://orcid.org/0000-0003-0118-1504 Universidade Federal de Campina Grande, Brasil E-mail: beatriz-queiroga@ outlook.com

Cinthya Nathaly Pereira Cardoso ORCID: https://orcid.org/0000-0001-6863-2707 Universidade Federal de Campina Grande, Brasil E-mail: cinthyanathaly.cn@gmail.com

Sara Beatriz Silva Batista

ORCID: https://orcid.org/0000-0002-7261-9465 Universidade Federal de Campina Grande, Brasil E-mail: sarajandisilva1@gmail.com

Agílio Tomaz Marques

ORCID: https://orcid.org/0000-0001-8364-5063 Universidade Federal de Campina Grande, Brasil E-mail: agiliotomaz@hotmail.com

Hugo Sarmento Gadelha ${ }^{1}$

ORCID: https://orcid.org/0000-0001-9414-0554 Universidad del Museo Social Argentino, Argentina E-mail: hugoscurso@uol.com.br

Hiran Mendes Castro Filho ${ }^{2}$

ORCID: https://orcid.org/0000-0002-1418-159X Universidad del Museo Social Argentino, Argentina E-mail: hirancastro@gmail.com

Raquel Formiga de Medeiros ${ }^{3}$

ORCID: https://orcid.org/0000-0002-1198-5015 Universidad del Museo Social Argentino, Argentina E-mail: raquelfdm@hotmail.com

Suzana Araújo dos Santos

ORCID: https://orcid.org/0000-0001-5955-9421 Universidade Federal de Campina Grande, Brasil

E-mail: suzana.santos2007@yahoo.com.br

\begin{abstract}
Resumo
Esse artigo tem como finalidade demonstrar a importância do gerenciamento dos resíduos sólidos da construção civil, os quais tem apresentado ao longo dos anos, grandes problemas ambientais que acontece principalmente devido a enorme quantidade produzida pela construção e a destinação inadequada. A partir da elaboração dessas leis que visam a proteção do meio ambiente, diversos setores área da construção civil vem adotando medidas visando diminuir os efeitos ao meio ambiente em resposta às imposições de normatização e da própria sociedade e essas ações, manifestam-se numa busca de finais aceitáveis em etapas como a reciclagem, a redução de energia e a redução de perdas. Nesse contexto, este trabalho objetiva fazer uma análise da gestão dos resíduos sólidos frente aos impactos causados ao meio ambiente. Diante dessa conjectura, esse estudo foi realizado por meio do método de abordagem dedutivo, através da pesquisa exploratória com a utilização de dados bibliográficos de natureza qualitativa, utilizando o método de procedimento documental. De acordo com os resultados encontrados, foi possível constatar a importância das leis que regularizam o descarte adequado dos resíduos sólidos da construção civil e da implementação de práticas que auxiliam na redução desses resíduos no meio ambiente. Entretanto, apesar desse esforço, o descarte de entulho na construção civil ainda tem muito a progredir para que haja reduções significantes diminuindo assim, o impacto no
\end{abstract}

\footnotetext{
${ }^{1}$ Doutorando pela Universidad del Museo Social Argentino.

2 Doutorando pela Universidad del Museo Social Argentino.

${ }^{3}$ Doutoranda pela Universidad del Museo Social Argentino.
} 
meio ambiente, e nesse sentido, é preciso que as leis de proteção ao meio ambiente sejam mais efetivas na fiscalização para que esse descarte seja feito de forma adequado.

Palavra-chave: Resíduos sólidos; Construção civil; Meio ambiente.

\begin{abstract}
This article aims to demonstrate the importance of managing solid waste from civil construction, which over the years has presented major environmental problems that occur mainly due to the enormous amount produced by construction and inadequate disposal. From the elaboration of these laws that aim to protect the environment, several sectors of civil construction have been adopting measures to reduce the effects on the environment in response to the impositions of regulation and society itself, and these actions are manifested in a search for acceptable ends in steps such as recycling, energy reduction and loss reduction. In this context, this work aims to analyze the management of solid waste against the impacts caused to the environment. Faced with this conjecture, this study was carried out through the method of deductive approach, through exploratory research with the use of bibliographic data of a qualitative nature, using the method of documental procedure. According to the results found, it was possible to verify the importance of laws that regulate the proper disposal of solid waste from civil construction and the implementation of practices that help to reduce this waste in the environment. However, despite this effort, the disposal of debris in civil construction still has a lot to progress so that there are significant reductions, thus reducing the impact on the environment, and in this sense, it is necessary that the environmental protection laws be more effective in the inspection so that this disposal is done properly.
\end{abstract}

Keywords: Solid waste; Civil construction; Environment.

\title{
Resumen
}

Este artículo tiene como objetivo demostrar la importancia del manejo de los residuos sólidos de la construcción, los cuales han presentado a lo largo de los años, grandes problemas ambientales que suceden principalmente por la enorme cantidad que produce la construcción y su disposición inadecuada. A partir de la elaboración de estas leyes que tienen como objetivo proteger el medio ambiente, varios sectores del área de la construcción civil han venido adoptando medidas para reducir los efectos sobre el medio ambiente en respuesta a las imposiciones de la normatividad y de la propia sociedad y estas acciones, se manifiestan en una buscar fines aceptables en pasos como el reciclaje, la reducción de energía y la reducción de pérdidas. En este contexto, este trabajo tiene como objetivo analizar la gestión de los residuos sólidos frente a los impactos causados al medio ambiente. En vista de esta conjetura, este estudio se realizó utilizando el método de enfoque deductivo, a través de una investigación exploratoria con el uso de datos bibliográficos de naturaleza cualitativa, utilizando el método de procedimiento de documento. De acuerdo con los resultados encontrados, se pudo constatar la importancia de leyes que regulen la disposición adecuada de los residuos sólidos de la construcción civil y la implementación de prácticas que ayuden a reducir estos residuos en el medio ambiente. Sin embargo, a pesar de este esfuerzo, la disposición de escombros en la construcción civil aún tiene un largo camino por recorrer para que existan reducciones significativas, reduciendo así el impacto en el medio ambiente, y en este sentido, es necesario que las leyes de protección ambiental sean más efectivas. en supervisión para que esta disposición se haga correctamente.

Palabras clave: Residuos sólidos; Construcción civil; Medio ambiente.

\section{Introdução}

Um dos principais fatores que contribuem para o aumento da geração de resíduos sólidos provenientes da construção civil, tem está relacionado ao crescimento desordenado da população do planeta, e as altas densidades demográficas nos centros urbanos junto ao desenvolvimento econômico mundial.

Como resultado desse crescimento desordenado temos o aumento do número de edificações é resultado da crescente demanda do mercado imobiliário. Sendo necessárias à implementação de medidas que regulamentem o descarte do entulho gerado pela construção civil para que possa ser garantir a sustentabilidade e preservação do meio ambiente (Grandin \& Costa).

Diante disso, a partir da aprovação da Política Nacional de Resíduos Sólidos - PNRS (Brasil, 2010a), passa a surgir uma nova perspectiva para o cenário nacional, pois, além da regulamentação da gestão adequada dos resíduos, essa lei passa a incluir também, questões para o desenvolvimento econômico e social, aliado a manutenção da qualidade ambiental.

É importante destacar que de acordo com essa política os Resíduos da Construção Civil (RCC), esses resíduos são: “os gerados nas construções, reformas, reparos e demolições de obras de construção civil, incluídos os resultantes da preparação e escavação de terrenos para obras civis”. (Brasil, 2010) 
De acordo com Filho et al. (2007) o despejo desapropriado desses resíduos sólidos nas cidades contribui para a destruição de mata ciliar nas margens de rios e córregos, poluição visual, proliferação de vetores causadores de doenças, como também possíveis contaminações de lençóis freáticos.

Diante dessa conjectura, esse artigo tem como objetivo principal analisar como se dá essa gestão dos resíduos sólidos da construção civil diante dos impactos causados ao meio ambiente.

Essa pesquisa foi desenvolvida através da utilização do método de abordagem dedutivo, o qual analisará, como se dá essa gestão dos resíduos sólidos da construção civil diante dos impactos causados ao meio ambiente. Também foi realizada uma análise exploratória por meio da pesquisa de dados bibliográficos de natureza qualitativa, a qual utilizou-se da análise de artigos, teses, revistas, dissertações e livros, e por fim foi utilizado o método de procedimento documental que foi feito por meio de analises de leis e projetos.

Por fim, para uma melhor compreensão esse estudo organiza-se em 4 capítulos, no primeiro capítulo, se faz necessário realizar uma análise histórica sobre o tratamento dos resíduos sólidos no Brasil provenientes da construção civil, no segundo capitulo foi feito um estudo de como é tratado os resíduos sólidos na lei brasileira, no terceiro capitulo buscou-se realizar uma análise dos impactos da construção civil ao meio ambiente e por fim no último capítulo foi realizado um breve levantamento das práticas para a redução dos resíduos sólidos gerados pela construção civil.

\section{Resíduos sólidos no Brasil}

\subsection{O que são resíduos sólidos da construção civil}

Inegavelmente, o setor da construção civil tem papel fundamental no desenvolvimento do país, entretanto, apesar do setor ser de suma importância é, também, uma das atividades humanas que mais consome recursos naturais - calcula-se, internacionalmente, que entre $40 \%$ e $75 \%$ dos recursos naturais existentes são consumidos por esse setor, causando, assim, uma enorme geração de resíduos. Só no Brasil, a construção gera 25\% do total desses resíduos (Mattes, 2019).

Os Resíduos da Construção Civil (RCC), segundo a Política Nacional de Resíduos Sólidos são: “os gerados nas construções, reformas, reparos e demolições de obras de construção civil, incluídos os resultantes da preparação e escavação de terrenos para obras civis" (Brasil, 2010).

O artigo $2^{\circ}$ da Lei 714/2017 informa que resíduos sólidos são os provenientes de construções tais como: argamassa; blocos cerâmicos; colas; compensados; concretos em geral; fiação elétrica. tijolos; gesso; metais; resinas; rochas; madeiras; forros; telhas; pavimento asfáltico; vidros; plásticos; solos; tintas; tubulações (São Gonçalo, 2017). Além disso, os resíduos podem ser classificados da seguinte forma, segundo o artigo $3^{\circ}$ da mesma lei:

I - Classe A - são os resíduos reutilizáveis ou recicláveis como agregados, tais como:

a) de construção, demolição, reformas e reparos de pavimentação e de outras obras de infraestrutura, inclusive solos provenientes de terraplanagem;

b) de construção, demolição, reformas e reparos de edificações: componentes cerâmicos (tijolos, blocos, telhas, placas de revestimento etc.), argamassa e concreto;

c) de processo de fabricação e/ou demolição de peças pré-moldadas em concreto (blocos, tubos, meio-fio etc.) produzidas nos canteiros de obras; II - Classe B - são os resíduos recicláveis para outras destinações, tais como plásticos, papel, papelão, metais, vidros, madeiras, embalagens vazias de tintas imobiliárias e gesso;

III - Classe C - são os resíduos para os quais não foram desenvolvidas tecnologias ou aplicações economicamente viáveis que permitam a sua reciclagem ou recuperação;

IV - Classe D - são resíduos perigosos oriundos do processo de construção, tais como tintas, solventes, óleos e outros ou aqueles contaminados ou prejudiciais à saúde, oriundos de demolições, reformas e reparos de clínicas radiológicas, instalações industriais e outros, bem como telhas e demais objetos e materiais que contenham amianto ou outros produtos nocivos à saúde (São Gonçalo, 2017). 
A indústria da construção civil contém características, e, dentre seus principais aspectos estão o alto desperdício e o enorme impacto ambiental causado em termos de volume de resíduos gerados e matéria-prima consumida. A maior parte dos profissionais da construção civil desconsidera a quantidade de resíduos sólidos gerados a partir da demolição e construção de obras civis e, quando tem conhecimento da poluição ambiental, não estão instruídos de como prosseguir com uma destinação seletiva dos resíduos, por meio de uma deposição correta e de uma triagem, separando os resíduos passíveis de reciclagem e/ou reutilização.

As deposições irregulares são habituais nos municípios brasileiros, frente a falta de alternativas para destinação ou disposição de forma correta, e causam desperdício de materiais nobres e altas despesas para as ações corretivas.

Entretanto, o novo cenário em formação carrega novas e grandes obrigações para todos os incluídos na rede de geração dos resíduos sólidos. A importância e a indispensabilidade de um ordenamento das questões ligadas à gestão de resíduos sólidos ocasionam na publicação de políticas públicas que dispõem sobre princípios, objetivos, instrumentos e diretrizes relativas ao assunto (São Paulo, 2012).

\subsection{Resíduos sólidos na lei brasileira}

Em agosto de 2010, com o objetivo de organizar os meios em que o país lidava com o lixo, para o seu gerenciamento, o congresso nacional aprovou a lei n $12.305 / 2010$, que criou a Política Nacional de Resíduos Sólidos (PNRS). Em 1999 ocorreu uma longa discursão devido o Projeto de Lei do Senado (PLS 354), iniciado pelo ex-senador Francisco Rollemberg, tal discursão perdurou 20 anos até chegar ao texto da lei.

A dispositivo traz conceitos modernos, como a responsabilidade compartilhada pelo tempo útil dos produtos, entre comerciantes, distribuidores, fabricantes, importadores, consumidores e poder público, o inovador sistema de logística prenuncia um compilado de procedimentos para viabilizar que resíduos sólidos retornem ao setor empresarial, que fora originado para reaproveitamento (eletrônicos) ou descarte para ambiente conveniente (pilhas e baterias). É considerada um marco legal para a gestão de resíduos sólidos no país.

Em conformidade com Godoy (2013, p. 6), a PNRS é um meio que:

Objetiva disciplinar, no seu conjunto, a questão dos resíduos sólidos. Ela estrutura todo um conjunto de andaimes sobre o qual se deve apoiar a reconstrução de todo o que diz respeito ao setor, até agora, matérias muito disseminadas na multiplicidade de entes oficiais. A PNRS está teoricamente alicerçada numa filosofia norteadora prática e coerente, a qual deverá dar as bases para o planejamento e gestão setorial que compreende, como razão de ser, a proteção do meio ambiente e seus recursos e a das comunidades, tudo dentro de um marco geossistêmico e integrado.

Esta lei é a condutora de todas as leis a normas especificas que se aplicam aos resíduos sólidos brasileiros, uma vez que instituiu a Política Nacional de Resíduos Sólidos (PNRS), tais políticas tem como objetivo responsabilizar as empresas pelos os seus resíduos até a destinação final. Além disso, determina quais são as empresas que devem elaborar um plano de gerenciamento de resíduos e para onde serão destinados esses materiais, como dispõem o artigo primeiro do regulamento:

Art. $1^{\circ}$ Esta Lei institui a Política Nacional de Resíduos Sólidos, dispondo sobre seus princípios, objetivos e instrumentos, bem como sobre as diretrizes relativas à gestão integrada e ao gerenciamento de resíduos sólidos, incluídos os perigosos, às responsabilidades dos geradores e do poder público e aos instrumentos econômicos aplicáveis (Brasil, 2010).

Existem outras legislações auxiliares que se submetem a lei $\mathrm{n}^{\circ}$ 12.305/2010, apesar de que boa parte destas normas foram criadas antes da PNRS. A lei n ${ }^{\circ}$ 6.938/81 conhecida como lei da Polícia Nacional do Meio Ambiente (PNMA), essa lei 
Research, Society and Development, v. 11, n. 2, e32711220994, 2022

(CC BY 4.0) | ISSN 2525-3409 | DOI: http://dx.doi.org/10.33448/rsd-v11i2.20994

traz ordem e instrumentos para preservar, melhorar e recuperar a qualidade ambiental. Os principais objetivos da PNMA são, manter o equilíbrio ecológico, administrar o uso dos recursos ambientais, proteger os ecossistemas, controlar atividades poluidores, a lei busca melhorar a qualidade de vida da população através do seu dispositivo, aplicando sanções aos poluidores que causaram danos ambientais, independentemente de culpa.

A lei dos crimes ambientais de $n^{\circ} 9.605 / 98$ foi publicada no dia 12 de fevereiro de 1998 com objetivo de reparar danos ambientais através de sanções penais e administrativas aos que praticam condutas que prejudicam o meio ambiente. Neste dispositivo se encontra as disposições sobre aplicação da pena e quais os tipos de crime.

Além das citadas, existem outras leis e normas que regulamenta o descarte e reaproveitamento adequado de resíduos sólidos, como o decreto n ${ }^{\circ}$ 4.074/2002, a lei n ${ }^{\circ}$ 11.445/2007 (Política Nacional de Saneamento Básico), portaria $n^{\circ} 274 / 19$ que regulamenta sobre a recuperação energética dos resíduos, portaria $\mathrm{n}^{\circ} 280$.

Apesar de todo esse aparato legal, o Brasil não mostrou evolução para a redução de produção dos resíduos sólidos. Pode-se observar que entre os anos de 2010 a 2019, os resíduos sólidos urbanos passaram de 67 milhões para 73 milhões de toneladas por ano, aumentando cerca de 19\%, sendo o sudeste a região que mais gera resíduos no país (Meu Resíduo, 2020).

É evidente que a gestão de resíduos não evolui proporcionalmente ao aumento populacional, percebe-se que a quantidade de resíduos sem coleta, sem destinação adequada e sem reaproveitamento, são cada vez maiores. Cerca de $90 \%$ dos resíduos gerados no Brasil são coletados, significando que ainda há cerca de 20 mil toneladas de resíduos que são descartados em local inapropriados, principalmente em rios e outras fontes de água, segundo o panorama da Abrelpe. (Senado Federal, 2014).

A industrialização e a urbanização principalmente a partir do século XIX foram os principais fatores influentes para o aumento de lixo nas cidades, pois aumentou-se o consumo nos centros urbanos devido ao crescimento populacional nesta região, somente em 1808 com a chegada na família real portuguesa começou-se a preocupação com saúde pública, fazendo a limpeza urbana avançar (Senado Federal, 2014).

Apesar disso o descarte dos resíduos até o século XXI é uma problemática, gerando danos ambientais nas águas e terrenos baldios, observa-se que até 2050 haverá um aumento de 50\% no montante de resíduo solido urbano em comparação ao ano de 2019, o país poderá alcançar 100 milhões de toneladas de resíduos em 2033, tais dados despertam um alerta urgente por políticas públicas que gerem um maior estimulo a não produção de matérias, e a reutilização dos que já existem (Meu Resíduo, 2020).

Na construção do ambiente urbano, a área formal das atividades construtivas facilmente se sobressai pelo seu grande consumo de recursos naturais e como resultado, a geração significativa de resíduos. Mesmo não sendo o setor de maior geração de resíduos, ele está dentro de uma atividade econômica consideravelmente impactante. Neste sentido, o emblema da Construção Sustentável não poderá ser levado a frente exclusivamente com a produção de prédios ícones e a produção da construção sustentável deve estar pensada para a não geração, a reutilização, a reciclagem e a correta destinação de seus resíduos.

O "marco legal" que exterioriza a assunto dos resíduos de construção é a Resolução de número 307, do Conselho Nacional do Meio Ambiente- CONAMA, aprovada em junho de 2002. Que de acordo com o Artigo $1^{\circ}$ resolve: Estabelecer diretrizes, critérios e procedimentos para a gestão dos resíduos da construção civil, disciplinando as ações necessárias de forma a minimizar os impactos ambientais.

Por outro lado, a Resolução CONAMA 307 exibe um modelo de gestão em que são estabelecidas responsabilidades para os agentes envolvidos: geradores, transportadores, áreas de destinação e municípios, cabendo a estes o desenvolvimento 
do plano municipal determinando diretrizes, critérios e procedimentos para os agentes envolvido (Portal Resíduos Sólidos, 2014).

Fazer uma análise que possa identificar as principais necessidades do país tem sido um dos grandes desafios que precisam ser superados, colocando em pratica o monitoramento dos resíduos gerados no Brasil. Isso acontece devido a contaminação do solo, rios e até mesmo o ar, gerados por várias industrias, sem ter o conhecimento das quantidades e os tipos de resíduos que estão enviando para o ambiente.

Com a Lei, existe o princípio da responsabilidade, o que faz com que a gestão seja compartilhada aos principais atores da sociedade. As empresas, bem como o setor público têm elevada importância para que as ações sejam realizadas. Cada um deles deve ter seu próprio plano para que as formas de destino sejam as mais adequadas para o ambiente. (BKR, 2020)

\section{Impactos da Construção Civil ao Meio Ambiente}

De acordo com o Urban World Forum (2002), a sustentabilidade urbana consegue ser definida baseada em um grupo de principalidades, como por exemplo: a superação da pobreza, a promoção da equidade, a melhoria das condições ambientais e a prevenção da sua degradação. Acrescenta-se também o fortalecimento da vitalidade cultural, do capital social e da cidadania; além das inter-relações com conteúdo de âmbito regional e global, tal como o efeito estufa, que tem ligação direta com a emissão de gases gerados na produção e disposição final de resíduos (McGranahan \& Satterthwaite, 2002; IPCC, 2011).

A gestão e a disposição de forma inapropriada dos resíduos sólidos acarretam impactos socioambientais, como a deterioração do solo, comprometimento dos corpos d'água e mananciais, aumento de enchentes, contribuição para a poluição do ar e propagação de vetores de importância sanitária nos centros urbanos e catação em condições insalubres nas ruas e nas áreas de disposição final (Besen et al., 2010).

O elevado volume de resíduos dispensados pela construção civil produz consequências ambientais expressivos por sua disposição de maneira desequilibrada e sem critérios científicos. Marques Neto (2005) apud Ferreira, Noschang e Ferreira (2009, p. 18) apresentam os impactos ambientais mais comuns, que são:

a) geração de áreas irregulares de descarte e o esgotamento dos "bota-foras" com a acomodação de elevados volumes de resíduos que prejudica diretamente as condições de tráfego de pedestres e veículos, a drenagem superficial e a obstrução de córregos que beneficia a multiplicação de vetores e doenças.

b) Áreas, que pela forma proibida da deposição, servem de encorajamento para a acomodação de outros materiais de origem industrial e domésticos, nem sempre inertes que incrementam o impacto ambiental.

c) Construtores clandestinos de obras menores espalham os resíduos por toda a extensão das estradas, das vias públicas, terrenos baldios e nas margens de rios e córregos intensificando os problemas urbanos como enchentes e tráfego congestionado.

d) Locais irregulares de disposição de Resíduos Construção/Demolição e outros materiais favorecem a degradação de áreas que deveriam ser preservadas, bem como, degradam os espaços urbanos.

Sem dúvidas, a falta de tratamento correto dos RCD produz graves problemas ambientais e sociais, uma vez que quando distribuídos de forma imprópria, como foi observado, geram o desgaste da qualidade de vida urbana, manifestando-se entre outras condições através dos alagamentos, deslizamentos de encostas e proliferação de vetores de doenças.

A fase de confecção de materiais de construção colabora da mesma forma a repercussão ambiental causado pelo setor de construção civil em razão da quantidade de poluição (poeira, $\mathrm{CO} \neg \neg 2$, etc.) que é produzida. A liberação de partículas de poeira está presente na maioria das atividades da construção civil, a partir da extração da matéria-prima, transporte, produção de materiais de construção, incluindo a execução das atividades em canteiro. 


\section{Práticas para a Redução dos Resíduos}

Conforme Tavares (2007), a área da construção civil vem adotando medidas que pretendem diminuir os efeitos ao meio ambiente em resposta às imposições de normatização e da própria sociedade. Tais ações manifestam-se numa busca de finais aceitáveis em etapas como a reciclagem, a redução de energia e a redução de perdas.

Um dos problemas habituais no ramo da construção civil é a perda de materiais e insumos durante a execução da obra, tal problemática ocasiona diversos problemas na execução da construção, inclusive o aumento na produção de resíduos, como barras de aço, entulho de parede, pedaços de blocos, sobras de areia, sobras de cimento, entre outros.

Esses resíduos, quando inadequadamente descartados, gerem diversos problemas ambientais. Por essa razão, é necessário adotar medidas que objetivem a diminuição de geração de resíduos na construção civil que são produzidos, visando um correto descarte.

Para a eliminação e diminuição de resíduos ocorrer de forma efetiva, requer que esse hábito seja implementado em toda a organização que trabalha na construção, não somente nos trabalhadores da execução (chefes de obras, pedreiros, serventes, entre outros) mas a partir daqueles que contribuem com o projeto civil na etapa inicial. Para isso é importante sistematizar a implantação desse hábito (Bueno, 2018).

A primeira forma é com o método dos “3Rs", ele consiste em Reduzir, Reutilizar e Reciclar. Reduzir significa avaliar a quantidade de materiais, ver se é necessário ou se pode trocar por outro, ou seja, economizar o que é possível. O segundo "R" consiste em evitar que vá para o lixo alguns materiais e utilizar de inovações para reutiliza-los na construção civil. Por fim, reciclar é aplicado nos casos onde não se podem aplicar os dois primeiros R's, mas poderão para por um processo para voltarem ao ciclo de vida de outro modo (Greenpeace, 2005).

Exatamente nesse contexto é essencial que haja um layouts de canteiro de obras, está relacionado as distâncias a serem feitas pelos colaboradores auxiliando em seus resultados, aprimorando os prazos e o corte de custos, devendo ser mediado pelos conceitos internos e externos. Como já mencionado, tem uma busca incessante sobre a questão da abolir os desperdícios, aumentando assim sua renda habilidade, esse processo na construção civil pode ser feito por alguns processos, estes sendo bem executados aprimoram a organização (Bueno, 2018).

O primeiro deles será a manutenção produtiva Total, a chamada TPM, esse sistema busca acabar com os problemas de causa antecedente, ele visa basicamente em acabar com as perdas, diminuir as paradas feitas gerando assim uma melhor condição, fazendo assim os custos da empresa serem menores, pois os processos serão perseverantes. O segundo processo será o de reparação da produção, o chamado 3P, busca criar um sistema que seja suficiente para a qualidade, produção e custo no seu sistema, como também a diminuição de desperdícios, será de produção enxuta (Lean). (Bueno, 2018)

É importante que a construção comercial busque a produção de reciclagem, pois os seus benefícios serão vistos quando observar um distintivo entre custos dos materiais gerados levados ao aterro e a reciclagem. Diante da Associação Brasileira para Reciclagem de Resíduos da Construção Civil e Demolição (Abrecon) é ainda primário no país, na pesquisa foi evidenciado que Brasil gera 850.000 t/mês de entulho.

Também é uma inovação o novo sistema de gestão o chamado Programa Brasileiro da Qualidade e Produtividade do Habitat (PBQP-h), que tem por objetivo administrar a situação dos resíduos em obra, perfeiçoando a sua efetivação, onde o implemento dessas ações pode aumentar cada vez mais a produtividade dessas empresas, e o sistema gera facilidade no controle e melhoria na qualidade e organização, Por isso todos esses sistemas de gestão devem serem implementados cada vez mais, com isso trazendo benefícios para empresa e para o meio ambiente (Brasil, 2020).

Sabado e Farias Filho (2011) destacam que o setor produtivo da construção civil vem aderindo ações nessa lógica, de forma a aprimorar a competitividade. Os autores apontam que a indústria da construção civil ficou vista durante muito tempo 
como geradora de vários problemas ambientes, em razão de fatores como a geração elevados volumes de resíduos e de entulhos; fabricação de cimento, etc.

A partir da ideia de sustentabilidade, as construções planejadas e executadas buscam formas de minimizar os impactos ambientais e fazer com que os imóveis atinjam um patamar de conforto elevado sem que, para isso, tenham que prejudicar o ambiente em que estejam inseridos, além de respeitarem a concepção de desenvolvimento de forma sustentável. [...] recursos como água e a enérgica elétrica, além da manutenção e a obtenção de insumos através de procedimentos de extração e de fabricação, devem ser obtidos a partir a concepção de sustentabilidade ambiental (Sabado \& Farias Filho, 2011, p. 32).

Dessa forma, um novo método de construção civil mais sustentável vem aparecendo e englobando novos pontos de vista para a área

\section{Considerações Finais}

De acordo com os resultados encontrados através da pesquisa, foi possível constatar a importância da implementação da lei no 12.305/2010, que criou a Política Nacional de Resíduos Sólidos com o objetivo principal de responsabilizar entes públicos e privados que fazem o descarte inadequado dos resíduos sólidos no meio ambiente.

Diante desses problemas de descarte inadequado, os diversos setores área da construção civil vem adotando medidas que pretendem diminuir os efeitos ao meio ambiente em resposta às imposições de normatização e da própria sociedade. Tais ações manifestam-se numa busca de finais aceitáveis em etapas como a reciclagem, a redução de energia e a redução de perdas.

Dessa forma, percebe-se que o setor produtivo da construção civil vem aderindo ações nessa lógica, de forma a aprimorar a competitividade. Os autores apontam que a indústria da construção civil ficou vista durante muito tempo como geradora de vários problemas ambientes, em razão de fatores como a geração elevados volumes de resíduos.

Apesar desse esforço, o descarte de entulho na construção civil ainda tem muito a progredir para que haja reduções significantes para que possa ser diminuído o impacto no meio ambiente, nesse sentido, é preciso que as leis de proteção ao meio ambiente sejam mais efetivas na fiscalização para que seja tomado um destino adequado desses resíduos.

\section{Referências}

Brasil. (1998). Lei $n^{\circ}$ 9.605, de 12 de fevereiro de 1998. Dispõe sobre as sanções penais e administrativas derivadas de condutas e atividades lesivas ao meio ambiente, e dá outras providências. Brasília, 12 de fevereiro de 1998. http://www.planalto.gov.br/ccivil_03/leis/19605.htm>

Brasil. (2010). Lei $n^{o}$ 12.305, de 2 de agosto de 2010. Institui a Política Nacional de Resíduos Sólido. Brasília, 2 de agosto de 2010. http://www.planalto.gov.br/ccivil_03/_ato2007-2010/2010/lei/112305.htm\#: :text=10\%20Esta\%20Lei\%20institui,pode r\%20p\%C3\%BAblico\%20e\%20aos\%20instrumentos

Brasil. (2017). Lei $n^{\circ}$ 714/2017: Reaproveitamento de resíduos na construção civil. VGR. https://www.vgresiduos.com.br/blog/lei-no-7142017-reaproveitamento-de-residuos-na-construcao-civil/

Brasil. (2020). Ministério do Desenvolvimento Regional. O PBPQ-H. https://www.gov.br/mdr/pt-br/assuntos/habitacao/pbqph/o-pbpq-h

Brasil. (2003). Resolução CONAMA no 307 de 05/07/2002. Estabelece diretrizes, critérios e procedimentos para a gestão dos resíduos da construção civil. Brasília. https://www.legisweb.com.br/legislacao/?id=98303

Bueno. M C. (2018). 7 práticas para diminuir os resíduos na construção. Templum. civilhttps://certificacaoiso.com.br/7praticas-para-diminuir-os-residuos-e-aumentar-o-lucro-na-construcao-civil 
BKR Ambiental. (2020). Resíduos da construção civil: um panorama sobre o descarte no Brasil. https://blog.brkambiental.com.br/residuos-da-construcao-civil/

Ferreira, D. D. M., Noschang, C. R. T., \& Ferreira, L. F. (2009). Gestão de Resíduos da Construção Civil e de Demolição: Contribuições para a Sustentabilidade Ambiental. In: CONGRESSO NACIONAL DE EXCELÊNCIA EM GESTÃO, 5. Niterói, RJ. Anais... Niterói, RJ.

Filho, R. P., Chiavini, P. P. R., Cimino, R. J. P., \& Guimarães, S. A. V. (2007). Gestão de resíduos da construção civil e demolição no município de São Paulo e normas existentes.

Godoy, M. R. B. (2013). Dificuldades para aplicar a Lei da Política Nacional de Resíduos Sólidos no Brasil. Caderno de Geografia, v. 23, n. 39.

Lopes, T. (2019). Direito e sustentabilidade ambiental: o regime jurídico aplicado à gestão dos rejeitos da construção civil. Revista Jus Navigandi, Teresina, ano 24, n. 5834, 22 jun. 2019. https://jus.com.br/artigos/74846

Marinho, A., \& Silva, C. (2012). Gerenciamento dos resíduos da construção e demolição: diretrizes para o crescimento sustentável da construção civil na região metropolitana do cariri cearense. E-tech, 5(1), 102-119, https://etech.sc.senai.br/edicao01/article/view/260/243

Marques Neto, J. C. (2005). Gestão dos resíduos da construção e demolição no Brasil. 2005. 162 f. Tese (Doutorado)Universidade de São Paulo, São Carlos.

Mattes, W. (2018). A construção civil e o desenvolvimento sustentável. Vivagreen. https://vivagreen.com.br/greenarq/construcao-civil-e-o-desenvolvimento-sustentavel/

Meu Resíduo. (2020). Panorama dos Resíduos Sólidos no Brasil - EDIÇÃO 2020. https://meuresiduo.com/geral/panoramados-residuos-solidos-no-brasil-edicao-2020/

Sabado, José O. S., \& Farias Filho, M. C. (2011). Ações de sustentabilidade influenciando o isomorfismo no campo da organização da indústria da construção civil. REUNA, 16(4), 27-42, http://Downloads/Sabado_Farias_2011_Acoes-desustentabilidade-infl_5594.pdf

Salles, C. (2013). A construção civil e seu impacto no meio ambiente. Jusbrasil. https://carollinasalle.jusbrasil.com.br/noticias/111940084/a-construcao-civil-e-seu-impacto-no-meio-ambiente

São Paulo. (2012). Secretaria do Meio Ambiente, 2012. Resíduos da Construção Civil e o estado de São Paulo. https://cetesb.sp.gov.br/sigor/wp-content/uploads/sites/37/2014/12/Res\%C3\%ADduos-da-Constru\%C3\%A7\%C3\%A3o-Civile-o-Estado-de-S\%C3\%A3o-Paulo.pdf

Tavares, L. P. M. (2007). Levantamento e análise da deposição e destinação dos resíduos da construção civil em Ituiutaba, MG. 160 f. Dissertação (Mestrado)-Faculdade de Engenharia Civil, Universidade Federal de Uberlândia, Uberlândia.

VGR. Resíduos sólidos: o que são, legislação a respeito e como destinar e tratar corretamente. 2020. https://www.vgresiduos.com.br/blog/residuos-solidos-o-que-sao-legislacao-a-respeito-e-como-destinar-e-tratar-corretamente/ 